\title{
Proliferation and Differentiation of Fetal Rat Pulmonary Epithelium in the Absence of Mesenchyme
}

\author{
Robin R. Deterding* and John M. Shannon* \\ *Division of Pulmonary Medicine, Department of Pediatrics, University of Colorado, The Children's Hospital, \\ and National Jewish Center for Immunology and Respiratory Medicine, Denver, Colorado 80218; and ${ }^{\ddagger}$ Department of Medicine, \\ National Jewish Center for Immunology and Respiratory Medicine, and Division of Pulmonary Sciences and Critical Care Medicine, \\ University of Colorado Health Science Center, Denver, Colorado 80206
}

\begin{abstract}
Previous studies have shown that pulmonary mesenchyme is required to maintain epithelial viability and to support branching morphogenesis and cytodifferentiation. We have examined whether pulmonary mesenchyme can be replaced by a medium containing a combination of soluble factors. Day 13-14 fetal rat distal lung epithelium was enzymatically separated from its mesenchyme, enrobed in EHS tumor matrix, and cultured for $5 \mathrm{~d}$ in medium containing concentrated bronchoalveolar lavage, EGF, acidic fibroblast growth factor, cholera toxin, insulin, and FBS (TGM), or in control medium containing only FBS. After $5 \mathrm{~d}$ in culture, marked growth and morphological changes occurred in epithelial rudiments cultured in TGM, whereas no changes were seen in controls. $\left[{ }^{3} \mathrm{H}\right.$ ] Thymidine incorporation and nuclear labeling indices during the last $24 \mathrm{~h}$ of culture confirmed that epithelial rudiments cultured in TGM had significant proliferative capacities. Evaluation of surfactant protein gene expression by Northern analysis, in situ hybridization, and immunocytochemistry demonstrated that distal lung epithelial differentiation progressed in TGM. Ultrastructural analysis demonstrated that fetal distal lung epithelium cultured in TGM contained lamellar bodies and deposited a basal lamina. These results are the first demonstration that sustained proliferation and differentiation of glandular stage distal pulmonary epithelium can proceed in the absence of mesenchyme. (J. Clin. Invest. 1995. 95:29632972.) Key words: lung • development • growth • differentiation - epithelium
\end{abstract}

\section{Introduction}

Lung organogenesis is initiated with a diverticulum of the primitive endodermal foregut that subsequently branches into surrounding splanchnic mesenchymal cells. Further growth and

Portions of this work have appeared in abstract form (1993. Mol. Biol. Cell. 4[Suppl.]:146a.

Address correspondence to Robin R. Deterding, M.D., National Jewish Center for Immunology and Respiratory Medicine, 1400 Jackson Street, K601, Denver, CO 80206. Phone: 303-398-1045; FAX: 303398-1806.

Received for publication 21 November 1994 and in revised form 1 February 1995.

J. Clin. Invest.

(c) The American Society for Clinical Investigation, Inc.

0021-9738/95/06/2963/10 \$2.00

Volume 95, June 1995, 2963-2972 branching of the primitive rudiments results in the development and differentiation of the entire bronchopulmonary epithelium. Though poorly understood, tissue recombination studies have shown that the subsequent proliferation, branching morphogenesis and diverse epithelial cytodifferentiation are orchestrated through specific interactions between pulmonary epithelium and mesenchyme (1-3). Additionally, pulmonary mesenchyme has been shown to have quantitative effects on epithelial development. When pulmonary mesenchyme is totally removed from distal pulmonary epithelium, the epithelium dies; when mesenchyme is re-associated with pulmonary mesenchyme, however, the degree of epithelial branching and cytodifferentiation is proportional to the quantity of mesenchyme (3). The inductive properties of pulmonary mesenchyme are further demonstrated by the induction of branching morphogenesis and distal pulmonary epithelial markers in tracheal epithelium re-associated with distal pulmonary mesenchyme $(1,4)$.

These observations raise questions concerning the molecular basis for the requirement of epithelial association with mesenchyme in lung development. Soluble factors may participate in epithelial-mesenchymal interactions through paracrine or juxtacrine release mechanisms. Using immunological and molecular biology techniques, a number of studies have localized the production of specific growth factors or expression of their receptors in the developing lung. Factors that have been identified include EGF (5), acidic and basic fibroblast growth factors $(\mathrm{aFGF} \text { and bFGF })^{1}(6)$, TGF- $\beta 1$ (7), keratinocyte growth factor (KGF) $(8,9)$ and PDGF $(10)$. Growth factors and fibroblast-derived conditioned media have also been used to stimulate both adult $(11,12)$ and late fetal $(13-15)$ alveolar type II cells, supporting a possible role for these factors in mediating epithelial-mesenchymal interactions.

Epithelial cells from the distal tips of the early glandular stage lung, while morphologically indistinguishable, are thought to differentiate into the distinct cell types populating the alveolar space and small airways. Elucidating the factors that regulate the proliferation and differentiation of these cells will provide information that is clinically relevant to premature infants, as well as pediatric lung disease, lung injury and repair, and lung cancer. The growth and differentiation of alveolar type II cells is particularly relevant to clinical issues surrounding premature infants, since type II cells produce pulmonary surfactant, a deficiency of which is conclusively linked to respiratory distress syndrome (RDS) of the neonate (16). Type II cells also serve

1. Abbreviations used in this paper: aFGF, acidic fibroblast growth factor; $D_{3}$, control medium: DME and 3\% FBS; EHS, Engelbreth-HolmSwarm tumor extracellular matrix; $\mathrm{FE}+5 \mathrm{~d}$, fetal epithelial rudiments cultured for $5 \mathrm{~d}$; I, insulin; KGF, keratinocyte growth factor; PAS, periodic acid-Schiff; SP, surfactant protein; TGM, total growth medium. 
as progenitors of the gas-exchanging type I cell, and are involved in ion transport in the alveolus $(17,18)$. In the present study we have sought to stimulate distal pulmonary epithelial proliferation and differentiation in the absence of mesenchyme. The results show that early fetal epithelial cells will actively proliferate in the absence of mesenchyme. This is accompanied by acquisition of morphological and biochemical markers consistent with progression to a late-gestational alveolar type II epithelial cell phenotype.

\section{Methods}

Animals. Timed-pregnant Sprague-Dawley rats were obtained from Charles Rivers Laboratories (Raleigh, NC). A sperm-positive vaginal smear confirmed mating and represented day 0 of gestation (day of birth $=$ day 22). Pregnant dams were sacrificed with a lethal intraperitoneal dose of pentobarbital and transection of the aorta. After a rapid delivery through an abdominal hysterectomy, the fetuses were weighed, then sacrificed by decapitation. Fetal age was confirmed by fetal weight at delivery (19). After removing the heart, trachea and lungs en bloc from the chest cavity, individual lobes of the lung were dissected free from the major airways and maintained on ice in sterile Tyrode's buffer containing the following antibiotics: $100 \mathrm{U} / \mathrm{ml}$ penicillin $\mathrm{G}, 100 \mathrm{U} / \mathrm{ml}$ streptomycin, $2.5 \mu \mathrm{g} / \mathrm{ml}$ amphotericin (all from GIBCO BRL, Gaithersburg, MD) and $10 \mu \mathrm{g} / \mathrm{ml}$ gentamicin sulfate (Sigma Chemical Co., St. Louis, MO). Lungs from littermates were pooled, but individual litters were analyzed independently for all experiments, except for RNA analysis, which required pooling rudiments from two or three litters to obtain sufficient quantities of RNA.

Fetal epithelial rudiment culture. Distal lung buds were dissected from day 13-14 fetuses using Moria surgical knifes (Fine Science Tools Inc., Foster City, CA) and placed on ice in sterile Tyrode's solution + antibiotics. The distal fetal epithelium was then enzymatically separated from the surrounding pulmonary mesenchyme by a 30-min incubation in dispase (Collaborative Biomedical, Bedford, MA) at $37^{\circ} \mathrm{C}$. The dispase was removed and four 1-ml aliquots of Tyrode's + antibiotics + charcoal-stripped FBS (CSFBS; GIBCO BRL) were used to repeatedly wash the distal fetal pulmonary epithelial rudiments. Two drops of $1 \mathrm{mg} / \mathrm{ml}$ DNase I (Sigma Chemical Co.) were added to the last wash and the mesenchyme was manually separated from the rudiments using tungsten needles (Fine Science Tools Inc.). To assure absolute removal of the mesenchyme a second 15-min incubation in dispase and a series of four Tyrode's + CSFBS washes were done. The fetal epithelial rudiments were transferred to DME and placed on ice.

Initial experiments were done using 24-well Falcon plates (Becton Dickinson, Lincoln Park, NJ) coated with $0.8 \mathrm{ml}$ of growth factorreduced Matrigel (Collaborative Biomedical) or growth factor reduced Engelbreth-Holm-Swarm (EHS) extracellular matrix prepared in our laboratory by the method of Kleinman et al. (20) with the additional ammonium sulfate precipitation step reported by Vukicevic et al. (21). Growth factor-reduced Matrigel and growth factor-reduced EHS matrix prepared in our laboratory performed identically in our experiments (data not shown). $1 \mathrm{~h}$ after coating the wells with matrix, the rudiments were transferred onto the matrix using finely drawn glass Pasteur pipettes, enrobed by covering them with a small quantity of matrix, and gently mixed to assure good rudiment-matrix contact. In subsequent experiments we refined our techniques and used $35-\mathrm{mm}$ Falcon dishes (Becton Dickinson). Each dish was coated with multiple (3-4 per dish) drops of $25 \mu \mathrm{l}$ growth factor reduced Matrigel. Using a finely drawn glass pipette, 5-6 fetal epithelial rudiments were placed on the matrix, enrobed by applying an additional $25 \mu \mathrm{l}$ of matrix over each area, and mixed gently before the matrix gelled.

Culture medium. DME containing a combination of soluble factors that has been shown to stimulate $\left[{ }^{3} \mathrm{H}\right]$ thymidine incorporation by adult type II cells (12) as well as their proliferation in low density culture (11) was compared to DME containing $3 \%$ FBS $\left(D_{3}\right)$. This total growth medium (TGM) contained the following: $50 \%$ (vol/vol) 15-fold con- centrated bronchoalveolar lavage fluid (BALF) prepared from adult rats (22), insulin $10 \mu \mathrm{g} / \mathrm{ml}$ (I), EGF $25 \mathrm{ng} / \mathrm{ml}$ (both from Collaborative Biomedical), cholera toxin $1 \mu \mathrm{g} / \mathrm{ml}$ (CT; ICN, Irvine, CA), bovine aFGF $200 \mathrm{ng} / \mathrm{ml}$ (R\&D Systems, Minneapolis, MN) and 3\% FBS. If the 24-well plate method was used $0.3 \mathrm{ml}$ of liquid medium was added to each well, whereas $1.5 \mathrm{ml}$ was added to $35-\mathrm{mm}$ dishes. The cultures were incubated at $37^{\circ} \mathrm{C}$ in $10 \% \mathrm{CO}_{2}$ and air for $5 \mathrm{~d}$. The 24-well method was used to evaluate thymidine incorporation and mRNA expression. Gross morphology, electron microscopy, immunocytochemistry, and in situ hybridization were evaluated in epithelial rudiments cultured in 35$\mathrm{mm}$ dishes.

Thymidine incorporation and autoradiography. The effect of TGM or $D_{3}$ on fetal epithelial rudiment DNA synthesis was assessed by measuring $\left[{ }^{3} \mathrm{H}\right]$ thymidine incorporation into DNA. $10 \mu \mathrm{Ci} / \mathrm{ml}\left[{ }^{3} \mathrm{H}\right]-$ thymidine (specific activity, $6.7 \mathrm{Ci} / \mathrm{mmol}$; New England Nuclear, Boston, MA) was added during the last $24 \mathrm{~h}$ of culture. To harvest the rudiments for thymidine incorporation and DNA analysis after labeling, liquid medium was removed, the wells or dishes were washed once with sterile PBS ( $\mathrm{pH} 7.4$ ), and the EHS matrix was enzymatically digested by incubation in $1.0 \mathrm{ml}$ of dispase at $37^{\circ} \mathrm{C}$ for $1 \mathrm{~h}$. Once released from the matrix, the rudiments from individual cultures were placed in microfuge tubes, pelleted by centrifugation at $300 \mathrm{~g}$ for $5 \mathrm{~min}$, washed once with PBS, and re-pelleted at $300 \mathrm{~g}$. The pellets were stored in $50 \mu \mathrm{l}$ of sterile PBS at $-70^{\circ} \mathrm{C}$. Before analysis, the samples were resuspended in $1.0 \mathrm{ml}$ of sterile PBS plus $1 \mu \mathrm{M}$ phenylmethylsulfonyl fluoride (PMSF), $5 \mu \mathrm{M} N$-ethylmaleimide (NEM; both from Sigma Chemical Co.), and $5 \mu \mathrm{M}$ EDTA and sonicated on ice to disrupt the pellet. Separate aliquots were taken for determination of $\left[{ }^{3} \mathrm{H}\right]$ thymidine incorporation and DNA content. Radiolabeled DNA was precipitated on ice for at least $2 \mathrm{~h}$ using equal volumes of cell lysate and $20 \%$ TCA (Sigma Chemical Co.). TCA-precipitable material was collected on a glass filter (Whatman GF/C, Maidstone, England) using a vacuum manifold (Hoefer Scientific Foundation, San Francisco, CA). The filters were washed three times with $10 \%$ TCA, followed by two washes with 95\% alcohol. Filters were placed in scintillation vials and counts per minute were obtained by liquid scintillation counting. DNA content was determined fluorimetrically using the procedure of Labarca and Paigen (23). The counts per minute (CPM) of incorporated $\left[{ }^{3} \mathrm{H}\right]$ thymidine were normalized to micrograms of DNA.

Rudiments processed for autoradiography were washed once with PBS, fixed in $4 \%$ paraformaldehyde in PBS, $\mathrm{pH} 7.4$, for $2-4 \mathrm{~h}$ at $4^{\circ} \mathrm{C}$, and embedded in paraffin. Sections 4-6 $\mu \mathrm{m}$ thick were deparaffinized, rehydrated, and dipped in Kodak NTB2 autoradiographic emulsion (Eastman Kodak Co., Rochester, NY). Autoradiograms were exposed for $2 \mathrm{wk}$, developed by standard methods, then counterstained with hematoxylin. Labeling indices were determined by counting the percent of labeled nuclei present in a section containing more than 50 cells; a cell was considered positive if more than 10 silver grains were present over a nucleus.

RNA isolation and Northern blot analysis. To obtain sufficient yields of RNA for Northern analysis, at least 50-60 fetal epithelial rudiments grown in TGM were required. Rudiments were harvested from EHS matrix as above, homogenized in $4 \mathrm{M}$ guanidinium isothiocyanate (GITC) with a Polytron (Brinkman Instruments, Westbury, NY) and stored at $-70^{\circ} \mathrm{C}$ until further use. RNA was isolated by centrifugation for $18 \mathrm{~h}$ at $150,000 \mathrm{~g}$ through a cushion of $5.7 \mathrm{M} \mathrm{CsCl}$. Purified RNA was fractionated by electrophoresis through a denaturing $1 \%$ agarose gel and blotted onto Nytran (Schleicher and Schuell, Keene, NH) by capillary action. Conditions for prehybridization, hybridization, and washing were identical to those described previously (24). The cloning and sequencing of the cDNAs for rat SP-A, SP-B, and SP-C have been previously described (25-27). To determine equivalence of RNA loading of Northern blots, we analyzed the expression of 28s rRNA (28). Autoradiograms were generated using Kodak XAR-5 film (Eastman Kodak Co.). To quantify differences in mRNA expression, a phosphorous screen was exposed to the radioactivity present on the blot and a direct quantitation of radioactive counts was performed using Molecular Dynamics ImageQuant software, version 3.22 (Molecular Dynamics, 
Sunnyvale, CA) Northern blots were reprobed after removing previous ${ }^{32} \mathrm{P}$-labeled cDNA by stripping them in $50 \%$ formamide and $6 \times \mathrm{SSC}$ at $65^{\circ} \mathrm{C}$ for $1.5 \mathrm{~h}$ and rinsing in $2 \times \mathrm{SSC}$. The removal of cDNA probe was confirmed by an overnight autoradiogram.

Immunocytochemistry. Rabbit polyclonal antibodies to rat SP-A (24), SP-D (29), and to human pro-SP-C (a generous gift of Dr. Jeffrey Whitsett) were used as markers of pulmonary epithelial cell differentiation. A murine IgG1 monoclonal antibody to vimentin, (antibody V9; Boehringer Mannheim Biochemicals, Indianapolis, IN) was used to assess mesenchymal contamination. Matrix-enrobed fetal rudiments grown for $5 \mathrm{~d}$ in culture with TGM were fixed in either acid alcohol (for SP-A, SP-D and vimentin staining) or $4 \%$ paraformaldehyde (proSP-C staining) for $2 \mathrm{~h}$ at room temperature, transferred to $70 \%$ ethanol, and stored at $4^{\circ} \mathrm{C}$ until paraffin embedding. Deparaffinized 4-6- $\mu \mathrm{m}$ sections were rehydrated through graded alcohols and treated with methanol and hydrogen peroxide to remove endogenous peroxidase. The sections were incubated in PBS containing 3\% goat serum (GIBCO BRL) for $20 \mathrm{~min}$ to block nonspecific binding sites. Antibodies were then incubated with the tissue sections overnight at $4^{\circ} \mathrm{C}$. Standard immunocytochemical methods for treatment with a secondary biotinylated antibody, streptavidin-horseradish peroxidase incubation, and diaminobenzidine addition were used as previously described (30). Sections were counterstained with hematoxylin and examined by light microscopy.

In situ hybridization. In situ hybridization was performed essentially as described by Wert et al. (31). Rudiments were fixed in freshly prepared $4 \%$ paraformaldehyde in RNase-free PBS for $4 \mathrm{~h}$ at $4^{\circ} \mathrm{C}$, dehydrated, and embedded in paraffin. Sections 4-6 $\mu \mathrm{m}$ thick were mounted on 3-aminopropyltriethoxysilane-coated slides and baked overnight at $56^{\circ} \mathrm{C}$. Sections were dewaxed in xylene, rehydrated through graded ethanols, rinsed consecutively in normal saline and PBS, then re-fixed in $4 \%$ paraformaldehyde. The re-fixed sections were rinsed twice in PBS, treated with $20 \mu \mathrm{g} / \mathrm{ml}$ proteinase $\mathrm{K}$ in $50 \mathrm{mM}$ Tris, $5 \mathrm{mM}$ EDTA for $5 \mathrm{~min}$ at room temperature, rinsed in PBS, re-fixed and rinsed as before, then acetylated with $0.25 \%$ acetic anhydride in $0.1 \mathrm{M}$ triethanolamine ( $\mathrm{pH} \mathrm{8.0)}$ for $10 \mathrm{~min}$ at room temperature. Sections were consecutively rinsed in PBS and normal saline, dehydrated through a graded series of ethanol, and air dried.

Radiolabeled sense and anti-sense riboprobes were transcribed from a full-length cDNA for rat SP-C (27) that was previously cloned into plasmid pGEM 4Z (Promega Biotech, Madison, WI). Riboprobes were transcribed using linearized template, components of the Riboprobe Gemini System (Promega), and [ ${ }^{35}$ S ]-UTP (specific activity 1,0001,500 Ci/mmol; New England Nuclear, Boston, MA). Template cDNA was removed with RNase-free DNase (Boehringer Mannheim), then the transcripts were reduced to 200-bp fragments by limited alkaline hydrolysis in $0.1 \mathrm{M}$ carbonate buffer $(\mathrm{pH} 10.2)$ at $60^{\circ} \mathrm{C}$ for the appropriate length of time. Unincorporated nucleotides were removed by passing the transcripts through Quick Spin Sephadex G-50 spin columns (Boehringer Mannheim, Indianapolis, IN). Probes were precipitated with ethanol in the presence of carrier yeast RNA (GIBCO BRL) and resuspended in $200 \mathrm{mM}$ dithiothreitol (DTT; Sigma Chemical Co.).

Sections were hybridized with $1.5 \times 10^{6} \mathrm{cpm}$ of either sense or anti-sense riboprobe in $15 \mu \mathrm{l}$ of a solution containing $50 \%$ formamide (Eastman Kodak Co.), $300 \mathrm{mM} \mathrm{NaCl}, 20 \mathrm{mM}$ Tris- $\mathrm{HCl}$ (pH 8.0), 5 mM EDTA, $10 \mathrm{mM} \mathrm{NaPO}_{4}(\mathrm{pH} \mathrm{8.0}), 10 \%$ dextran sulfate, $1 \times$ Denhardt's (both from 5 prime-3 prime, Boulder, $\mathrm{CO}$ ), and $0.5 \mathrm{mg} / \mathrm{ml}$ yeast RNA. Sections were coverslipped and hybridized in humidified chambers for $18 \mathrm{~h}$ at $55^{\circ} \mathrm{C}$. Hybridized sections were washed at high stringency in $50 \%$ formamide, $2 \times \mathrm{SSC}, 10 \mathrm{mM}$ DTT at $65^{\circ} \mathrm{C}$ for 30 min, rinsed three times in $0.5 \mathrm{M} \mathrm{NaCl}, 10 \mathrm{mM}$ Tris $\mathrm{HCl}$ ( $\mathrm{pH} 7.5$ ), 5 mM EDTA at $37^{\circ} \mathrm{C}$, then treated with $20 \mu \mathrm{g} / \mathrm{ml} \mathrm{RNase} \mathrm{A} \mathrm{and} 5 \mathrm{U} / \mathrm{ml}$ RNase T1 (both from Sigma Chemical Co.) for $30 \mathrm{~min}$ at $37^{\circ} \mathrm{C}$. The slides were rinsed in $0.5 \mathrm{M} \mathrm{NaCl}, 10 \mathrm{mM}$ Tris $\mathrm{HCl}(\mathrm{pH} 7.5), 5 \mathrm{mM}$ EDTA at $37^{\circ} \mathrm{C}$ for $15 \mathrm{~min}$, then the high stringency wash was repeated, followed by successive washes in $2 \times$ SSC, $1 \mathrm{mM}$ DTT and $0.1 \times \mathrm{SSC}$, $1 \mathrm{mM}$ DTT for $15 \mathrm{~min}$ at room temperature. The sections were dehydrated, air dried, then dipped in Kodak NTB-2 nuclear track emulsion.

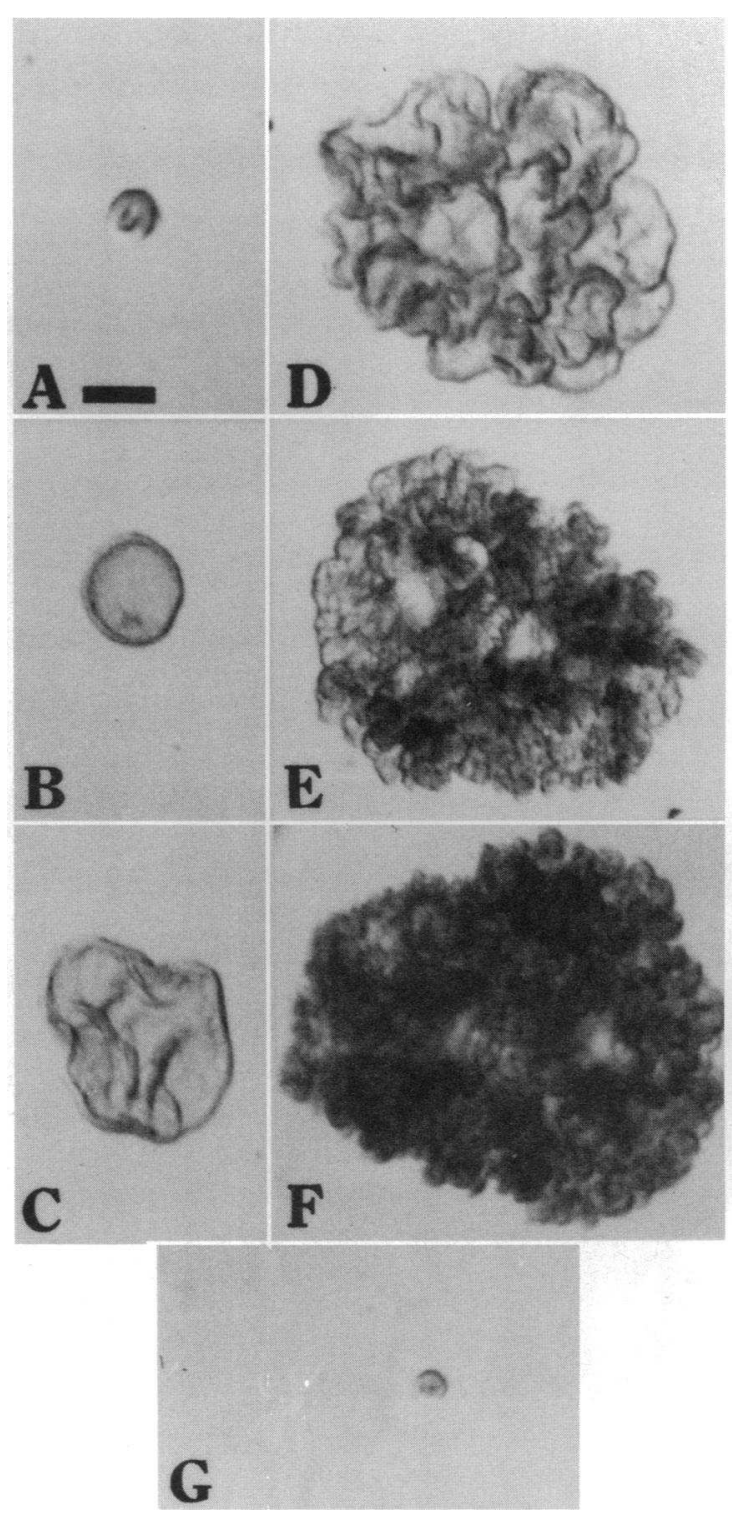

Figure 1. Time course of morphologic changes seen in isolated day 14 fetal epithelial rudiments cultured in total growth medium (TGM) or control medium $\left(D_{3}\right) . A-F$ represent the gross morphologic changes seen in a representative single epithelial rudiment cultured $5 \mathrm{~d}$ in TGM, whereas $G$ illustrates the changes seen in a rudiment cultured for $5 \mathrm{~d}$ in control medium. ( $A$ ) A freshly isolated epithelial rudiment separated from mesenchyme at time 0 . (B) After $24 \mathrm{~h}$ in culture there has been cystic growth of the rudiment. $(C)$ By $48 \mathrm{~h}$ the rudiment has enlarged and developed folds. $(D)$ After $72 \mathrm{~h}$ of culture there was a significant increase in size with distinct lobule formation. $(E$ and $F)$ By 96 and $120 \mathrm{~h}$, respectively, the rudiment has continued to enlarge with further subdivision of the lobules into a more complex three-dimensional structure. $(G)$ A rudiment cultured for $120 \mathrm{~h}$ in $\mathrm{D}_{3}$ shows no growth and a slight attenuation in size when compared with $A$. There is a marked difference in size and morphology from the rudiment in $1 \mathrm{~F}$ cultured $120 \mathrm{~h}$ in TGM. Bar, $200 \mu \mathrm{m}$.

Autoradiograms were developed after 3-10 d with Kodak D19 developer at $16^{\circ} \mathrm{C}$ and fixed with Kodak fixer. Sections were lightly counterstained with hematoxylin and viewed for photomicrography.

Electron microscopy. Epithelial rudiments were cultured in TGM for $5 \mathrm{~d}$, fixed for $2 \mathrm{~h}$ in $2 \%$ glutaraldehyde, and $1 \%$ paraformaldehyde in phosphate buffer at $4^{\circ} \mathrm{C}$, and stored in $0.1 \mathrm{M}$ sodium cacodylate 


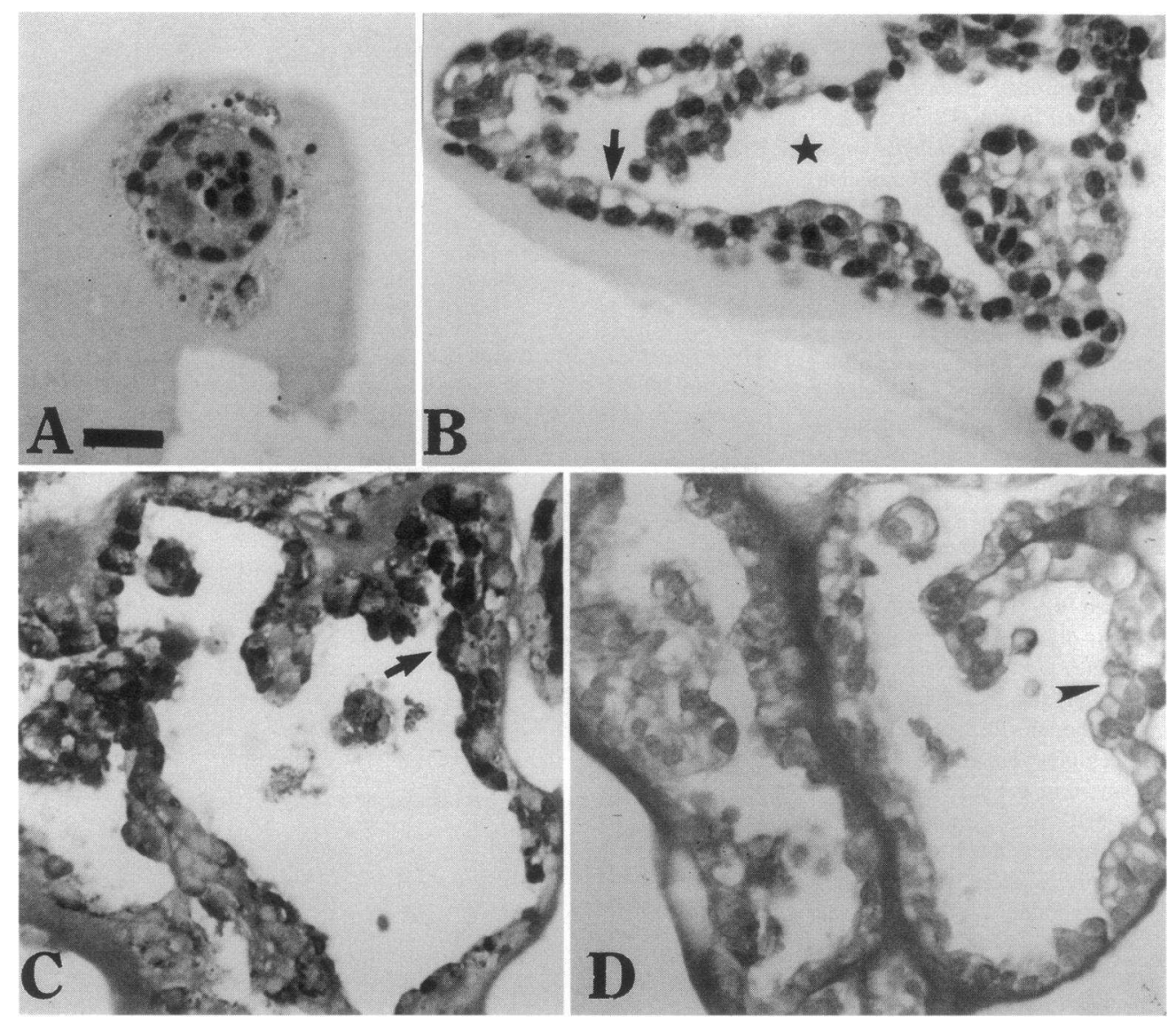

Figure 2. Light microscopy of cultured distal pulmonary epithelial rudiments. Day 14 fetal epithelial rudiments devoid of mesenchyme were cultured for $5 \mathrm{~d}$ in TGM or $D_{3} . A$ and $B$ represent epithelial rudiments cultured in $\mathrm{D}_{3}$ and TGM, respectively, and stained with hematoxylin and eosin. $C$ and $D$ show epithelial rudiments cultured for $5 \mathrm{~d}$ in TGM and stained with periodic acid-Schiff (PAS) without $(C)$ or with $(D)$ diastase pretreatment. (A) A rudiment cultured in $D_{3}$ shows many cells with pyknotic nuclei, cellular debris, and a few healthy epithelial cells without obvious glycogen stores. The stained material surrounding the rudiments is the EHS matrix. (B) A portion of a rudiment cultured in TGM. The cuboidal epithelium is healthy, contains clear apical areas consistent with apparent glycogen stores (arrow), forms a lumen (star), and displays apical polarity as would be expected in vivo at this stage of lung development. $(C)$ A rudiment cultured in TGM stained with PAS. PAS positive staining can be seen apically in the majority of epithelial cells (arrow). (D) To confirm the presence of glycogen, a serial section of the rudiment in $C$ was treated with diastase, then stained with PAS. Ablation of the PAS stain (arrowhead) confirms the presence of glycogen. Bar, $21 \mu \mathrm{m}$.

buffer. Samples were postfixed in $1.5 \%$ osmium tetroxide, rinsed in sodium maleate buffer, and stained en bloc with uranyl acetate. Samples were embedded in Lufts 3:7 mixture of LX-112 (Ladd Research Industries, Burlington, VT). Thin sections were stained with lead citrate and uranyl acetate and examined on a Phillips 400 electron microscope.

Statistical analysis. When data were compared between TGM and $D_{3}$ epithelium, a two-tailed paired $t$ test was used and significance was established at $P<0.01$. Labeling indices were averaged and meaned for epithelium grown in TGM.

\section{Results}

Gross morphology. To determine the capacity of distal fetal pulmonary epithelium to grow in the absence of pulmonary mesenchyme, day 13 or 14 fetal epithelial rudiments were enzymatically separated from mesenchyme, enrobed in growth factor-reduced Matrigel and cultured for $5 \mathrm{~d}$ in medium containing soluble factors (TGM) or control liquid medium $\left(D_{3}\right)$. Fig. 1 illustrates the changes in gross morphology seen in epithelial rudiments cultured in TGM versus $D_{3}$. A single epithelial rudiment in TGM at the initiation of culture is shown in Fig. $1 A$, and subsequently at $24,48,72,96$, and $120 \mathrm{~h}$ in Fig. $1, B-$ $F$, respectively. As can be seen, significant, complex, threedimensional growth occurred over the 5-d culture period in
TGM when compared to the initial epithelial rudiment (Fig. 1 $A)$. Conversely, $1 G$ illustrates an epithelial rudiment that was cultured in $\mathrm{D}_{3}$ for $5 \mathrm{~d}$. Such rudiments were typically reduced in size compared to rudiments at the initiation of culture.

Light microscopy. Light microscopy of epithelial rudiments cultured in the absence of mesenchyme for $5 \mathrm{~d}$ in $\mathrm{D}_{3}$ or TGM is seen in Fig. 2. Epithelium cultured in $D_{3}$ (Fig. $2 A$ ) shows numerous cells with pyknotic nuclei and cellular debris. Rudiments cultured in TGM (Fig. $2 B$ ), however, showed healthy cuboidal epithelial cells, some of which exhibited clear areas consistent with glycogen stores. The identity of these areas as glycogen was confirmed by the abolition of periodic acid-Schiff (PAS) staining by pretreatment with diastase (Fig. 2, C and D) (32). The epithelium also appeared polarized, and obvious lumina were formed. The morphological features seen in rudiments grown in TGM were consistent with those seen in vivo during the canalicular stage of lung development.

Proliferation. Epithelial rudiments grown for a total of $5 \mathrm{~d}$ were labeled with $\left[{ }^{3} \mathrm{H}\right.$ ] thymidine during the last $24 \mathrm{~h}$ of culture, then either processed for analysis of thymidine incorporation or fixed and processed for autoradiography and determination of an epithelial labeling index. Rudiments grown in TGM had a sixfold increase in $\left[{ }^{3} \mathrm{H}\right]$ thymidine incorporated per microgram 


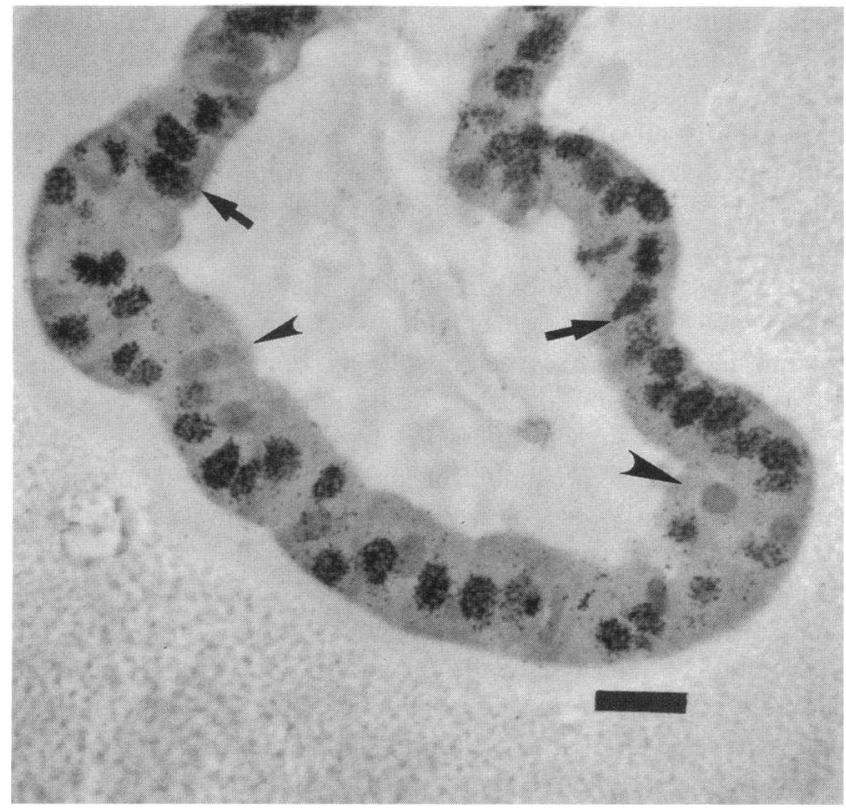

Figure 3. Representative autoradiogram of a distal pulmonary epithelial rudiment cultured in TGM. Day 14 fetal epithelial rudiments were cultured $5 \mathrm{~d}$ in TGM, labeled with $\left[{ }^{3} \mathrm{H}\right]$ thymidine the last $24 \mathrm{~h}$ of culture, fixed in $4 \%$ paraformaldehyde, sectioned, and processed for autoradiography. Nuclei containing greater than 10 silver grains were considered positive. The majority of nuclei demonstrate positive labeling (arrow) though not all nuclei are positive (arrowhead). Bar, $21 \mu \mathrm{m}$.

DNA when compared with rudiments cultured in $\mathrm{D}_{3}(n=5 ; P$ $<0.01$ ). Fig. 3 shows a representative autoradiogram of a rudiment grown for $5 \mathrm{~d}$ in TGM. Many of the epithelial cells have entered or transversed S phase during the 24-h labeling period. The average labeling index of rudiments grown in TGM was $85 \% \pm 6 \%$ SEM $(n=3)$. Conversely, rudiments exposed to $\mathrm{D}_{3}$ were small and labeled cells were rarely detected.

Differentiation. To determine whether the proliferating epithelial cells in rudiments grown in TGM would continue differentiation into a distal pulmonary epithelial phenotype, we examined surfactant protein mRNA and protein expression. The presence of surfactant protein-C (SP-C) is a specific marker for alveolar type II cells in the adult rodent and a presumed marker for distal pulmonary epithelium in the fetal rat lung $(33,34)$. Fig. 4 illustrates a Northern blot of mRNA obtained from freshly isolated fetal (F) day 15, 18, 19; and 21 lungs and epithelial rudiments isolated at fetal day 13 and 14 and grown for $5 \mathrm{~d}$ in TGM (FE+5d). SP-A, SP-B, and SP-C mRNAs were not detectable by Northern analysis in freshly isolated day 15 fetal lungs and presumably would not be detectable at the time of rudiment isolation in a fetal day 13 or 14 lung. As gestation progresses, however, expression of all three surfactant proteins mRNAs increases (19). Day 13-14 epithelial rudiments cultured in TGM showed greater levels of SP-A, SP-B, and SP-C expression than freshly isolated in vivo controls of the same overall age. A direct comparison between cultured epithelial rudiments devoid of mesenchyme and in vivo controls was not possible due to the mRNA contributed by the mesenchyme in the controls. However, fetal day 14 rudiments cultured for $5 \mathrm{~d}$ in TGM had SP-C mRNA expression that was increased 16fold over the level seen in freshly-isolated fetal day 19 lungs. The magnitude of this increase is unlikely to be due to the

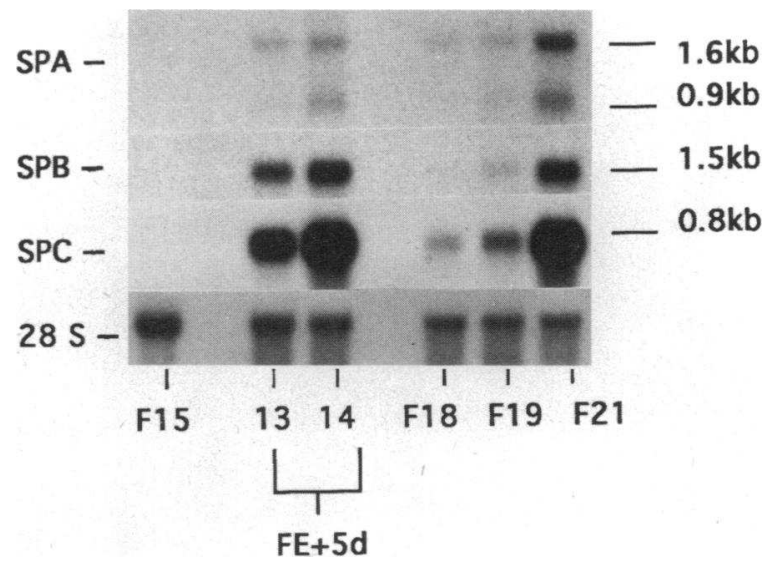

Figure 4. Northern blot for surfactant protein mRNAs. Lungs from freshly isolated fetal days 15 (F15), 18 (F18), 19 (F19), and 21 (F21) served as in vivo controls. Day 13 and 14 fetal epithelial rudiments were cultured in TGM for $5 \mathrm{~d}(\mathrm{FE}+5 \mathrm{~d})$. Tissues were homogenized in guanidinium isothiocyanate and total RNA was isolated by centrifugation through a $\mathrm{CsCl}$ cushion. RNA was fractionated by electrophoresis, transferred to a Nytran membrane, probed with cDNAs for SP-A, SPB, SP-C, and $28 \mathrm{~s}$ rRNA; $2.5 \mu \mathrm{g}$ of RNA were loaded per lane. The freshly isolated in vivo control lungs show no expression for SP-A, SPB, or SP-C at F15. By F18, expression for all of the surfactant protein mRNAs can be detected, and this expression increases by F21. Cultured day 13 and 14 fetal epithelial rudiments $(F E+5 d)$ expressed all three surfactant protein mRNAs. As mRNA for the surfactant proteins was not detected in F15, it is assumed that expression would not have been detected at the initiation of the epithelial rudiment culture at fetal day 13 or 14.

dilution of signal by mesenchymal RNA, suggesting that distal epithelial differentiation not only occurs, but may also be accelerated in this culture system.

In situ hybridization was done to ascertain the percentage and distribution of epithelial cells in rudiments grown in TGM that expressed SP-C mRNA. Fig. $5 A$ shows that most cells in the TGM-cultured epithelial rudiments exhibited intense SP-C mRNA expression. Interestingly, though the majority of cells were positive for SP-C mRNA, there was not ubiquitous expression among the cell population. A spatial relationship to this heterogeneous distribution was apparent, with a more intense signal present in cells at the tips, and negative cells present toward the center of the rudiment. This spatial relationship can also be seen in the cultured fetal day 14 lung shown in Fig. 5 $C$. Hybridization with an equal amount of radiolabeled sense SP-C transcript gave no signal (Fig. $5 B$ ).

To examine whether surfactant proteins could be produced in cultured TGM rudiments, immunocytochemical staining for SP-A, SP-C, and SP-D were performed. Fig. 6, $A$ and $B$ show sections of epithelial cells cultured for $5 \mathrm{~d}$ in TGM and immunostained with SP-A and SP-D, respectively. Staining for both SP-A and SP-D was present, but not all cells were positive, again suggesting heterogeneity among cells in cultured rudiments. Fig. $6 C$ depicts immunocytochemical stain for proSP-C combined with autoradiography for incorporation of [ ${ }^{3} \mathrm{H}$ ] thymidine during the last $24 \mathrm{~h}$ of culture. Numerous, but not all, cells were positive for pro-SP-C protein and many cells were both labeled with $\left[{ }^{3} \mathrm{H}\right]$ thymidine and positive for pro-SP-C.

To assure that our epithelium was free of mesenchymal 

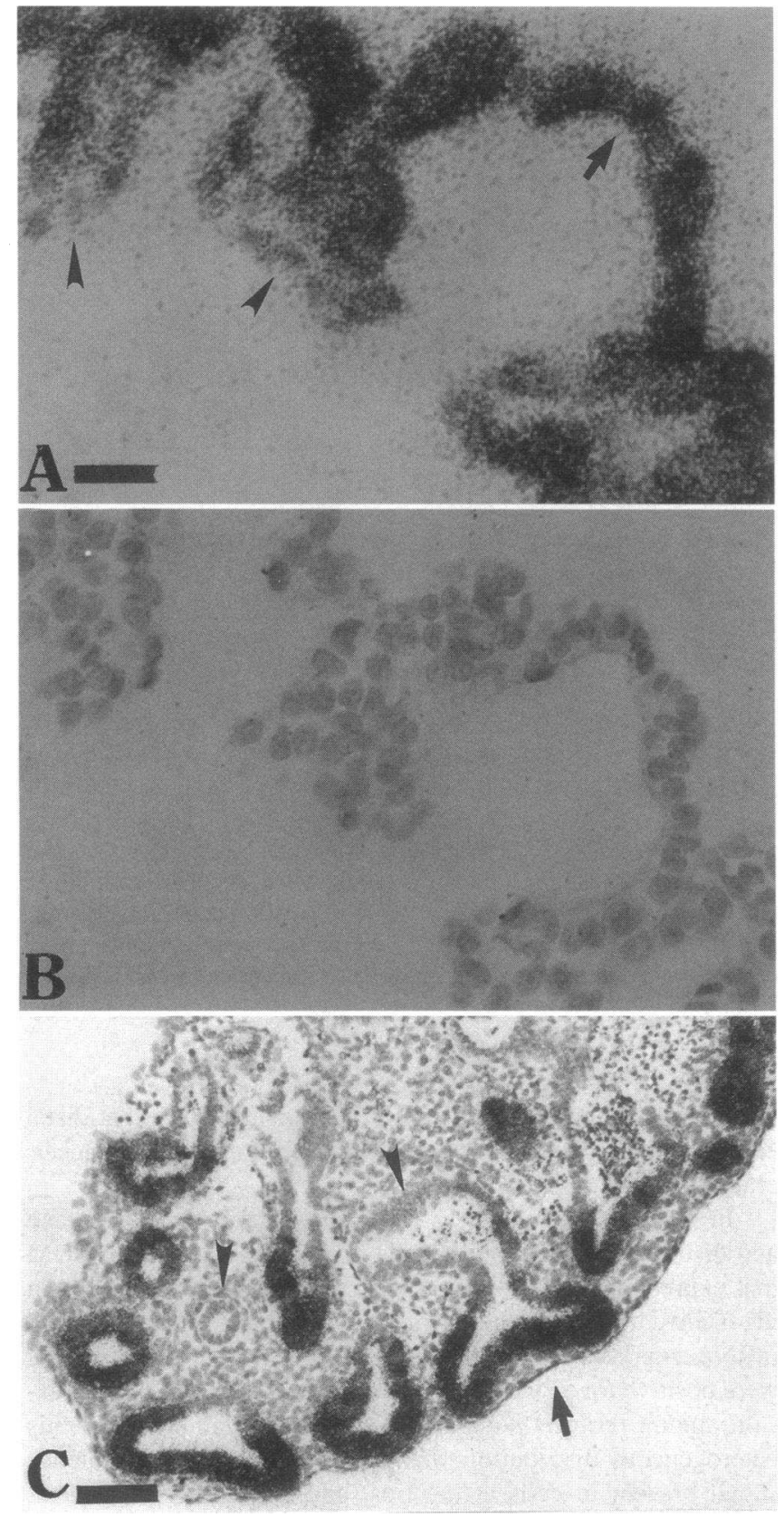

Figure 5. In situ hybridization for SP-C mRNA in day 14 fetal epithelial rudiments cultured for $5 \mathrm{~d}$ in TGM. To demonstrate the expression of SP-C in intact lung explant cultures, fetal day 13 lungs were cultured in DME $+1 \%$ FBS for $5 \mathrm{~d}$. Epithelial rudiments and lung explants were harvested, fixed in paraformaldehyde, sectioned, hybridized with ${ }^{35} \mathrm{~S}$ labeled sense or anti-sense rat SP-C riboprobes, and processed for autoradiography. ( $A$ ) A epithelial rudiment cultured in TGM and hybridized with anti-sense SP-C riboprobe. Most cells are positive for SP-C mRNA (arrow), with a more intense signal seen at the distal tips. However, some cells located along the innermost aspects of the rudiment show only faint signal (arrowhead). (B) An adjacent section taken from the same rudiment seen in A but hybridized with sense SP-C riboprobe. There is no detectable hybridization after an exposure identical to that seen in $A$. Bar: $(A$ and $B) 21 \mu \mathrm{m}$. $(C)$ Fetal day 13 lung grown in explant culture and probed with anti-sense SP-C. SP-C mRNA expression is seen in the distal tips (arrow) and not in the more proximal epithelium (arrowhead), similar to the expression seen in epithelial rudiments cultured in TGM. Bar: (C) $33 \mu \mathrm{m}$. contamination, immunocytochemical staining with an antibody to the intermediate filament protein vimentin was used. Fig. 6 $D$ demonstrates typical vimentin staining in a day 14 fetal rat lung. Nearly all of the mesenchymal cells stained positive for vimentin, whereas the epithelium was devoid of positive staining. A representative cross-section of a rudiment grown in TGM and stained with vimentin is shown in Fig. $2 E$. There was no detectable staining present in multiple sections, thus establishing the mesenchyme-free conditions of our epithelial culture system. In addition to vimentin staining, contaminating mesenchyme can easily be identified in a epithelial culture by a distinctly different growth and spreading pattern. Cultures were routinely screened visually for mesenchymal contamination, and intermittently subjected to vimentin staining as an added control for mesenchymal contamination.

Ultrastructure. Cells were examined ultrastructurally for characteristics of alveolar type II cells. Fig. 7 shows electron micrographs of epithelial cells grown for $5 \mathrm{~d}$ in TGM. The cells show glycogen deposits and structures consistent with lamellar bodies located both intracellularly and lumenally (Fig. $7 A$ ). Ultrastructural evidence for lamellar body secretion was also observed (Fig. 7 B ). Additionally, ultrastructural examination showed that the cells were able to deposit a basement membrane (Fig. $7 C$ ).

\section{Discussion}

Virtually all previous data have supported the concept that pulmonary mesenchyme is essential for epithelial proliferation, branching, and cytodifferentiation in the developing lung. The importance of mesenchyme has been documented in tissue separation and recombination studies, where attempts to maintain early fetal lung epithelium in the absence of pulmonary mesenchyme results in epithelial death $(1-3,35)$. Moreover, Masters removed mesenchyme in a quantitative manner and found an association between increasing amounts of mesenchyme and the extent of epithelial branching and lamellar body formation (3). Thus a minimal quantity of mesenchyme has been assumed necessary to support epithelial proliferation, with increased amounts of mesenchyme being required for epithelial branching and cytodifferentiation. We hypothesized that this requirement for mesenchyme was mediated by soluble factors. Cultured adult alveolar type II cells $(11,36)$ and epithelium from other fetal organs such as salivary gland (37) and tooth (38) are capable of proliferation and differentiation in the absence of mesenchyme when soluble growth factors are present. We have demonstrated for the first time that the requirement for pulmonary mesenchyme in distal epithelial proliferation and differentiation in the early gestation (glandular stage) fetal rat lung can be replaced by a combination of soluble factors (TGM) and an extracellular matrix. When cultured in TGM, the pulmonary epithelial rudiments resembled or exceeded in differentiation aged-matched in vivo distal lung epithelium. This is in contrast to fetal lung explant cultures, where expression of morphological markers of differentiation is somewhat retarded. This suggests that lung mesenchyme may be producing inhibitory factors, or, alternatively that TGM contains maximal levels of the stimulatory factors normally present in vivo. Similar to previous reports of pulmonary epithelium cultured devoid of mesenchyme, our distal fetal pulmonary epithelium was poorly maintained in control medium lacking all additions except serum $(2,3)$. These data suggest the possible role of juxtacrine and 


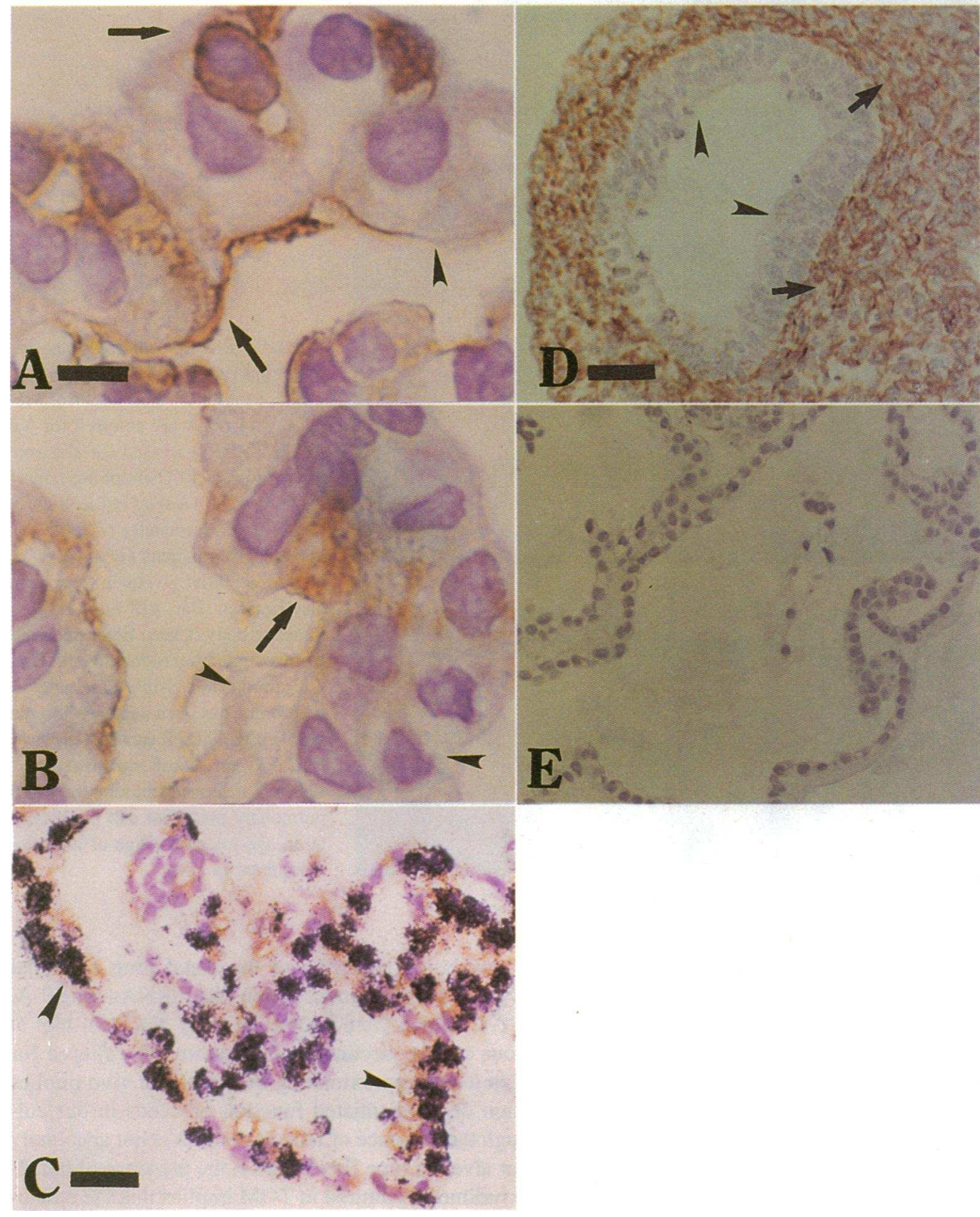

Figure 6. Immunocytochemical staining for SP-A, pro-SP-C, SP$D$, and vimentin. Day 14 fetal epithelium was cultured for $5 \mathrm{~d}$ in TGM, labeled with $\left[{ }^{3} \mathrm{H}\right]-$

thymidine the last $24 \mathrm{~h}$, and fixed in paraformaldehyde or acid alcohol. Sections were stained with antibodies to SP-A, SP-D, pro-SP$C$, and vimentin using standard biotinylated antibody, streptavidinperoxidase immunocytochemical techniques. Freshly isolated day 14 fetal lung was also isolated and processed as an in vivo control for vimentin staining. $(A)$ A portion of an epithelial rudiment cultured for $5 \mathrm{~d}$ in TGM and immunostained with an antibody to SP-A protein. Positive staining can be seen in some (arrow) but not all cells (arrowhead). (B) An adjacent section from the rudiment seen in A stained with an antibody to SP-D. Heterogeneous staining of the cell population was again seen, as positive (arrow) and negative (arrowhead) cells are seen. Bar: $(A$ and $B) 21 \mu \mathrm{m}$. (C) After immunostaining for pro-SP-C, the section was dipped in emulsion, and processed for autoradiography. Many, but not all cells, were positive for pro-SP-C. Many cells were both labeled with $\left[{ }^{3} \mathrm{H}\right]-$ thymidine and positive for proSP-C (arrowhead), demonstrating that differentiated SP-C positive cells were undergoing DNA synthesis. Bar, $5.8 \mu \mathrm{m}$. (D) Freshly isolated day 14 fetal lung immunostained for vimentin. The mesenchyme shows widespread positive staining (arrow), while the epithelium shows no detectable staining (arrowhead). (E) A fetal epithelial rudiment cultured in TGM for $5 \mathrm{~d}$ contains no positive vimentin staining, demonstrating that the culture was not contaminated by mesenchyme. Bar: $(D$ and $E) 21 \mu \mathrm{m}$.

paracrine growth factor release as mediators of epithelial-mesenchymal interactions during lung development.

Fibroblasts secrete undefined factors that are known to stimulate late-gestation fetal pulmonary epithelial cells (13) and adult alveolar type II cells (39). Unfortunately, the presence of fibroblasts in lung explant cultures and the potential for fibroblast contamination in isolated late-gestation fetal epithelial cultures prepared by differential adherence techniques $(40,41)$ can confound interpretation of the epithelial response to exogenous growth factors. Epithelial rudiments devoid of mesenchyme can reliably be obtained from the distal tip of glandular stage fetal rat lungs and thus circumvent this problem. This allows a deter- mination of the direct effects of individual soluble factors on the developing pulmonary epithelium.

Growth factors have been demonstrated to stimulate DNA synthesis and proliferation of adult rat type II cells in vitro (11, 36). The factors that constitute the ingredients found in TGM have also been shown to stimulate proliferation in isolated adult type II cells in low density culture (11). Specifically, BALF and $\mathrm{aFGF}$ have been reported to be the most potent stimulating factors of $\left[{ }^{3} \mathrm{H}\right]$ thymidine in cultured adult alveolar type II cells (36). The role of aFGF in TGM may be crucial to fetal epithelial cell proliferation. Recent studies in which the FGF receptor 2 containing the IIIb splice variant of the third Ig loop was ren- 


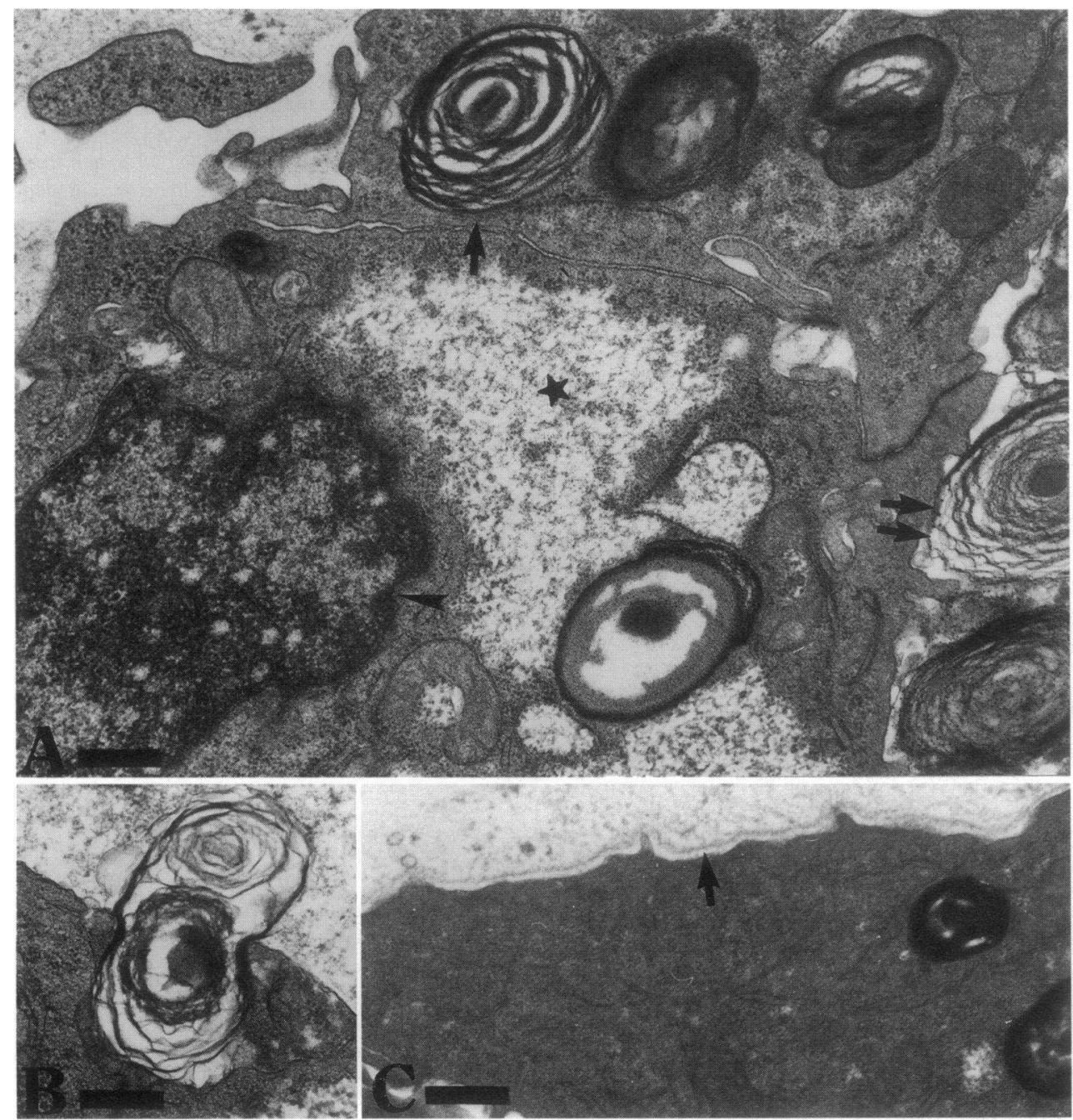

Figure 7. Electron micrographs of epithelial rudiments cultured in TGM. Epithelial rudiments from fetal day 14 rats were cultured for $5 \mathrm{~d}$ in TGM and processed for electron microscopy. ( $A$ ) Osmophilic lamellar bodies can be seen intracellularly (arrow) and lumenally (double arrow). The nucleus (arrowhead) and intracellular glycogen (star) can also be seen. Bar, $415 \mathrm{~nm}$. (B) A lamellar body is seen being secreted from an epithelial rudiment cell. Bar, $450 \mathrm{~nm}$. (C) A visible basement membrane has been deposited on the basal epithelial cell surface (arrow). Bar, $500 \mathrm{~nm}$. These ultrastructural findings are consistent with the distal pulmonary epithelial cell phenotype at an age-matched stage of lung development in vivo. dered inactive by targeted dominant-negative over-expression resulted in severe to complete abrogation of lung branching (42). This variant of FGF receptor 2 will bind both aFGF and KGF (43). Late-gestation fetal pulmonary epithelial cells have also been isolated and cultured in CT, I, or EGF, each of which has been shown to stimulate $\left[{ }^{3} \mathrm{H}\right]$ thymidine incorporation $(14$, 15). The role of EGF in fetal lung development is unclear. While some studies suggest that EGF stimulates branching morphogenesis in lung explant culture $(5,44)$, others have demonstrated that EGF reduces branching (45).

Mesenchyme is believed to direct the commitment of epithelial cells to cytodifferentiate into the appropriate phenotype through inductive interactions (38). Since SP-A, SP-B and SP-C were not detectable by Northern analysis in day 13-14 fetal lung, we wished to determine whether TGM could provide instructive signals in epithelial cells in the absence of mesenchyme. We were particularly interested in SP-C expression, since SP-C mRNA has been localized only to the type II cell in the adult rodent (33) and the distal epithelium in the fetus $(31,34)$, and is considered a tissue-specific differentiation marker for pre-alveolar type II cells. However, in contrast to Northern analysis, mRNAs for SP-A, SP-B and SP-C can be detected in the fetal rat lung by reverse transcription PCR by day 13 of gestation $(4,46)$. Thus in our cultures TGM is sup- porting the permissive induction of the distal lung epithelial phenotype. Nevertheless, demonstration that mRNAs for SP-A, SP-B, and SP-C, which were undetectable by Northern blot at the start of our culture, accumulated in rudiments cultured for $5 \mathrm{~d}$ in TGM to levels approximating those seen in vivo implies that maturation of differentiated function proceeds in our cultures. Although the presence of lamellar bodies is not absolutely diagnostic for alveolar type II cells (47), the presence of lamellar bodies in rudiments cultured in TGM implies that the epithelial cells have initiated synthesis of surfactant phospholipids. This further supports the concept that epithelial cells cultured in TGM progress along a normal distal lung differentiated pathway.

Interaction with an extracellular matrix has been shown to be important in the differentiation of many epithelial cell types. We enrobed our epithelial rudiments in EHS matrix, which is composed primarily of laminin, type IV collagen, heparan sulfate proteoglycan, and nidogen (20). It has also been shown that growth factors such as EGF, TGF-b, bFGF, IGF, and nerve growth factor are present in EHS, and that most of these factors can be eliminated by ammonium sulfate precipitation (21). Accordingly, we used growth factor-reduced EHS in our cultures to eliminate the possible contribution of these growth factors. The possibility still exists, however, that some unknown 
growth factors remain in this matrix preparation. We do not believe that matrix-associated growth factors had a significant direct effect on our rudiments, since growth factor-reduced EHS was incapable of supporting epithelial growth in control medium. Thus any such factors would have to work synergistically with factors found in TGM.

Distribution of epithelial cells expressing surfactant proteins or their mRNAs was not homogeneous in rudiments grown in TGM. SP-C mRNA and protein were preferentially expressed in the more distal epithelium, as occurs in vivo (31). These data combined with our immunostaining observations, suggest that different cell populations may be present and that the spatial relationship of different epithelial phenotypes is maintained. Alternatively, the morphologically indistinguishable distal epithelial cells seen on days 13-14 may represent precursor cells that follow separate differentiated pathways in TGM. It is also possible that different soluble factors are responsible for distinct inductive pathways of epithelial differentiation.

In summary, we have shown that glandular stage pulmonary epithelial cells can proliferate to form three-dimensional acinar structures in the absence of pulmonary mesenchyme, and that the constituent cells differentiate in a manner consistent with the formation of alveolar type II cells. We believe this culture system provides an ideal model for studying the role of soluble factors and extracellular matrix in mediating epithelial-mesenchymal interactions in the developing lung. Since the interaction of epithelium and mesenchyme is critical to lung development in vivo, determining those factors that stimulate epithelial proliferation and differentiation may be clinically relevant to understanding and treating the premature infant with bronchopulmonary dysplasia or congenital pulmonary anomalies.

\section{Acknowledgments}

We appreciate the support of Robert Mason, the processing of electron microscopy tissue samples by Janet Pfeiffer and Janet Oliver at the University of New Mexico, the laboratory assistance of Lynn Cunningham, Karen Edeen, Yiqian Wu, and Chris Jacoby, and the secretarial expertise of Peggy Hammond in preparing this manuscript.

This work was supported by Grants HL-45011, RG-217N and 5 P30 HD-27827, and performed in the Anna Perahia Adatto Clinical Research Center of the National Jewish Center for Immunology and Respiratory Medicine. Robin Deterding is supported by the Parker B. Francis foundation.

\section{References}

1. Spooner, B. S., and N. K. Wessells. 1970. Mammalian lung development: interactions in primordium formation and bronchial morphogenesis. J. Exp. Zool. 175:445-454.

2. Taderara, J. V. 1967. Control of lung differentiation in vitro. Dev. Biol. 16:489-512.

3. Masters, J. R. W. 1976. Epithelial-mesenchymal interaction during lung development: the effect of mesenchymal mass. Dev. Biol. 51:98-108.

4. Shannon, J. M. 1994. Induction of alveolar type II cell differentiation in fetal tracheal epithelium by grafted distal lung mesenchyme. Dev. Biol. 166:600614.

5. Seth, R., L. Shum, F. Wu, C. Wuenschell, F. L. Hall, H. C. Slavkin, and D. Warburton. 1993. Role of epidermal growth factor expression in early mouse embryo lung branching morphogenesis in culture: antisense oligodeoxynucleotide inhibitory strategy. Dev. Biol. 158:555-559.

6. Han, R. N., J. Liu, A. K. Tanswell, and M. Post. 1992. Expression of basic firoblast growth factor and receptor: immunolocalization studies in developing rat fetal lung. Pediatr. Res. 31:435-440.

7. Pelton, R. W., Saxena, B., Jones, M., Moses, H.L., and Gold, L.I. 1991. Immunohistochemical localization of TGFB1, TGFB2, and TGFB3 in the mouse embryo: expression patterns suggest multiple roles during embryonic development. J. Cell Biol. 115:1091-1105.

8. Orr-Urtreger, A., M. T. Bedfor, T. Burakova, E. Arman, Y. Zimmer, A. Yayon, D. Givol, and P. Loni. 1993. Developmental localization of the splicing alternatives of fibroblast growth factor receptor-2 (FGFR-2). Dev. Biol. 158:475486.

9. Mason, I. J., F. Fuller-Pace, R. Smith, and C. Dickson. 1994. FGF-7 (keratinocyte growth factor) expression during mouse development suggests roles in myogenesis, forebrain regionalization and epithelial-mesenchymal interactions. Mech. Dev. 45:15-30.

10. Han, R. N., C. Mawdsley, P. Souza, A. K. Tanswell, and M. Post. 1992. Platelet-derived growth factors and growth-related genes in rat lung. III. Immunolocalization during fetal development. Pediatr. Res. 31:323-329.

11. Leslie, C. C., K. McCormick-Shannon, R. J. Mason, and J. M. Shannon. 1993. Proliferation of rat alveolar epithelial cells in low density primary culture. Am. J. Respir. Cell Mol. Biol. 9:64-72.

12. Leslie, C. C., K. McCormick-Shannon, P. C. Robinson, and R. J. Mason 1985. Stimulation of DNA synthesis in cultured rat alveolar type II cells. Exp. Lung Res. 8:53-66.

13. Stiles, A. D., B. T. Smith, and M. Post. 1986. Reciprocal autocrine and paracrine regulation of growth of mesenchymal and alveolar epithelial cells from fetal lung. Exp. Lung Res. 11:165-177.

14. Fraslon, C., T. Lacaze-Masmonteil, V. Zupan, B. Chailley-Heu, and J. R. Bourbon. 1993. Fetal rat lung type II cell differentiation in serum-free isolated cell culture: modulation and inhibition. Am. J. Physiol. 264:L504-L516.

15. Jassal, D., N. N. Han, I. Caniggia, M. Post, and A. K. Tanswell. 1991. Growth of distal fetal rat lung epithelial cells in a defined serum-free medium. In Vitro Cell. Dev. Biol. 27A:625-632.

16. Mason, R. J., M. C. Williams, and J. H. Widdicombe. 1984. Cell culture systems for studying RDS. In Respiratory Distress Syndrome. K. O. Raivio, N. Hallman, K. Kouvalainen, and I. Valimaki, editors. Academic Press, New York. 87-96.

17. Mason, R. J., M. C. Williams, J. H. Widdicombe, M. J. Sanders, D. S. Misfeldt, and L. C. Berry. 1982. Transepithelial transport by pulmonary alveolar type II cells in primary culture. Proc. Natl. Acad. Sci. USA. 79:6033-6037.

18. Mason, R. J., M. C. Williams, and J. H. Widdicombe. 1982. Secretion and fluid transport by alveolar epithelial cells. Chest. 81:615S-635S.

19. Schellhase, D. E., P. A. Emrie, J. H. Fisher, and J. M. Shannon. 1989. Ontogeny of surfactant apoproteins in the rat. Ped. Res. 26:167-174.

20. Kleinman, H. K., M. L. McGarvey, L. A. Liotta, P. G. Robey, K. Tryggvason, and G. R. Martin. 1982. Isolation and characterization of type IV procollagen, laminin, and heparin sulfate proteoglycans from the EHS sarcoma. Biochemistry. 21:6188-6193.

21. Vukicevic, S., H. K. Kleinman, F. P. Luytem, A. B. Roberts, N. S. Roche, and A. H. Reddi. 1992. Identification of multiple active growth factors in basement membrane matrigel suggests caution in interpretation of cellular activity related to extracellular matrix components. Exp. Cell Res. 202:1-8.

22. Leslie, C. C., K. McCormick-Shannon, and R. J. Mason. 1989. Bronchoalveolar lavage fluid from normal rats stimulates DNA synthesis in rat alveolar type II cells. Am. Rev. Respir. Dis. 139:360-366.

23. Labarca, C., and K. Paigen. 1980. A simple, rapid, and sensitve DNA assay procedure. Anal. Biochem. 102:344-352.

24. Schellhase, D. E., and J. M. Shannon. 1991. Effects of maternal dexamethasone on expression of SP-A, SP-B, and SP-C in the fetal rat lung. Am. J. Respir. Cell Mol. Biol. 4:304-312.

25. Sano, K., J. Fisher, R. J. Mason, Y. Kuroki, J. Schilling, B. Benson, and D. Voelker. 1987. Isolation and sequence of a cDNA clone for the rat pulmonary surfactant-associated protein (PSP-A). Biochem. Biophys. Res. Commun. 144:367-374.

26. Emrie, P. A., J. M. Shannon, R. J. Mason, and J. H. Fisher. 1989. cDNA and deduced amino acid sequence for the rat hydrophobic pulmonary surfactantassociated protein, SP-B. Biochim. Biophys. Acta. 994:215-221.

27. Fisher, J. H., J. M. Shannon, T. Hoffman, and R. J. Mason. 1989. Nucleotide and deduced amino acid sequence of the hydrophobic surfactant protein SP$\mathrm{C}$ from the rat: expression in alveolar type II cells and homology with SP-C from other species. Biochim. Biophys. Acta. 995:225-230.

28. Erickson, J. M., C. L. Rushford, D. J. Dorney, G. N. Wilson, and R. D. Schmickel. 1981. Structure and variation of human ribosomal DNA: molecular analysis of cloned fragments. Gene. 16:1-9.

29. Shimizu, H., J. H. Fisher, P. Papst, B. Benson, K. Lau, R. J. Mason, and D. R. Voelker. 1992. Primary structure of rat pulmonary surfactant protein D: cDNA and deduced amino acid sequence. J. Biol. Chem. 267:1853-1857.

30. Deterding, R. R., S. Hiroshi, J. H. Fisher, and J. M. Shannon. 1994. Regulation of surfactant protein $\mathrm{D}$ expression by glucocorticoids in vitro and in vivo. Am. J. Respir. Cell Mol. Biol. 10:30-37.

31. Wert, S. E., S. W. Glasser, T. R. Korfhagen, and J. A. Whitsett. 1993. Transcriptional elements from the human SP-C gene direct expression in the primordial respiratory epithelium of transgenic mice. Dev. Biol. 156:426-443.

32. Sheenhan, D. C., and B. B. Hrapchak. 1980. Theory and Practice of Histotechnology. The C.V. Mosby Co., St. Louis, MO. 
33. Kalina, M., R. J. Mason, and J. M. Shannon. 1992. Surfactant protein C is expressed in alveolar type II cells but not in Clara cells of rat lung. Am. J. Respir. Cell Mol. Biol. 6:595-600.

34. Wohlford-Lenane, C. L., P. L. Durham, and J. M. Snyder. 1992. Localization of surfactant-associated protein C (SP-C) mRNA in fetal rabbit lung tissue by in situ hybridization. Am. J. Respir. Cell Mol. Biol. 6:225-234.

35. Rudnick, D. 1933. Developmental capacities of the chick lung in chorioallantoic grafts. J. Exp. Zool. 66:125-154.

36. Leslie, C. C., K. McCormick-Shannon, and R. J. Mason. 1990. Heparinbinding growth factors stimulate DNA synthesis in rat alveolar type II cells. Am. J. Respir. Cell Mol. Biol. 2:99-106.

37. Nogawa, H., and Y. Takahashi. 1991. Substitution for mesenchyme by basement-membrane-like substratum and epidermal growth factor in inducing branching morphogenesis of mouse salivary epithelium. Development (Camb.). 112:855-861.

38. Couwenhoven, R. I., and M. L. Snead. 1994. Early determination and permissive expression of amelogenin transcription during mouse mandibular first molar development. Dev. Biol. 164:290-299.

39. Panos, R. J., J. S. Rubin, S. A. Aaronson, and R. J. Mason. 1993. Keratinocyte growth factor and hepatocyte growth factor are heparin-binding growth factors for alveolar type II cells in fibroblast conditioned medium. J. Clin. Invest. 92:969-977.

40. Batenburg, J. J., C. J. M. Otto-Verberne, A. A. W. Have-Opbroek, and W. Klazinga. 1988. Isolation of alveolar type II cells from fetal rat lung by differential adherence in monolayer culture. Biochim. Biophys. Acta. 960:441453.

41. Kresch, M. J., D. W. Dynia, and I. Gross. 1987. Culture of differentiated and undifferentiated type II cells from fetal rat lung. Biochim. Biophys. Acta. 930:19-32.

42. Peters, K., S. Werner, X. Liao, S. Wert, J. Whitsett, and L. Williams. 1994. Targeted expression of a dominant negative FGF receptor blocks branching morphogenesis and epithelial differentiation of the mouse lung. EMBO (Eur. Mol. Biol. Organ.) J. 13(14):3296-3301.

43. Miki, T., D. P. Bottaro, T. P. Flemin, C. L. Smith, W. H. Burgess, A. M Chan, and S. A. Aaronson. 1992. Determination of ligand-binding specificity by alternative splicing: Two distinct growth factor receptors encoded by a single gene. Proc. Natl. Acad. Sci. USA. 89:246-250.

44. Warburton, D., R. Seth, L. Shum, P. G. Horcher, F. L. Hall, Z. Werb, and H. C. Slavkin. 1992. Epigenetic role of epidermal growth factor expression and signalling in embryonic mouse lung morphogenesis. Dev. Biol. 149:123-133.

45. Ganser, G. L., G. P. Stricklin, and L. M. Matrisian. 1991. EGF and TGF-a influence in vitro lung development by the induction of matrix-degrading metalloproteinases. Int. J. Dev. Biol. 35:453-461.

46. Wang, J., P. Souza, M. Kuliszewski, A. K. Tanswell, and M. Post. 1994. Expression of surfactant proteins in embryonic rat lung. Am. J. Respir. Cell Mol. Biol. 10:222-229.

47. Mason, R. J., and M. C. Williams. 1980. Phospholipid composition and ultrastructure of A549 cells and other cultured pulmonary epithelial cells of presumed type II cell origin. Biochim. Biophys. Acta. 617:36-50. 